\title{
16S rRNA and 16S to 23S Internal Transcribed Spacer Sequence Analyses Reveal Inter- and Intraspecific Bifidobacterium Phylogeny
}

\author{
NATHALIE LEBLOND-BOURGET,${ }^{1} \dagger$ HERVE PHILIPPE, ${ }^{2}$ IRENE MANGIN,${ }^{1}$ AND BERNARD DECARIS ${ }^{1 *}$ \\ Laboratoire de Génétique et Microbiologie, INRA U. A. 952, Université Henri-Poincaré, F-54506 Vandoeuvre-lès- \\ Nancy, ${ }^{1}$ and Laboratoire de Biologie Cellulaire, Université de Paris-Sud, F-91405 Orsay Cedex, ${ }^{2}$ France
}

\begin{abstract}
In the last few years many attempts have been made to differentiate more than 20 Bifidobacterium species. It has been recognized that identification of bifidobacterial species is problematic because of phenetic and genetic heterogeneities. In order to contribute to our understanding of Bifidobacterium taxonomy, we studied Bifidobacterium phylogeny by performing both $16 \mathrm{~S}$ rRNA and $16 \mathrm{~S}$ to $23 \mathrm{~S}$ (16S-23S) internally transcribed spacer (ITS) sequence analyses. In this study, we determined 16S rRNA sequences of five Bifidobacterium strains representing four species, and compared them with the sequences available in the GenBank database, and used them to construct a distance tree and for a bootstrap analysis. Moreover, we determined the ITS sequences of 29 bifidobacterial strains representing 18 species and compared these sequences with each other. We constructed a phylogenetic tree based on these sequence data and compared this tree with the tree based on 16S rRNA sequence data. We found that the two trees were similar topologically, suggesting that the two types of molecules provided the same kind of phylogenetic information. However, while 16S rRNA sequences are a good tool to infer interspecific links, the 16S-23S rDNA spacer data allowed us to determine intraspecific relationships. Each of the strains was characterized by its own ITS sequence; hence, 16S-23S rRNA sequences are a good tool for strain identification. Moreover, a comparison of the ITS sequences allowed us to estimate that the maximum level of ITS divergence between strains belonging to the same species was $13 \%$. Our data allowed us to confirm the validity of most of the Bifidobacterium species which we studied and to identify some classification errors. Finally, our results showed that Bifidobacterium strains have no tRNA genes in the 16S-23S spacer region.
\end{abstract}

Members of the genus Bifidobacterium are widespread in nature, and the habitats of these organisms range from sewage $(53,54)$ to human and animal intestines $(28,31,44,52,56)$. The ability to catabolize hexose by a particular pathway via fructose phosphate phosphoketolase is important for recognizing members of this genus $(8,51)$. In the last few years many ways to differentiate Bifidobacterium species have been developed. Numerical taxonomy analysis, which requires data for many characteristics, has been used to circumscribe clusters and to describe strains. Morphological traits, carbohydrate metabolism data, DNA G+C contents (3), electrophoretic patterns $(22,48,50)$, serologic data $(44,58,59)$, cell wall compositions (22), and rRNA gene restriction patterns (26) have been used to subdivide Bifidobacterium species (for a review, see reference 3 ). Major advances in our understanding of the taxonomy of members of the genus Bifidobacterium have come from the DNA-DNA hybridization studies performed by Scardovi et al. $(49,54,55,57)$. However, problems with the identification of Bifidobacterium species are compounded by evidence that there is phenotypic and genetic heterogeneity in these species (6). Moreover, differentiation of some species has often been based on differences in only a few traits, which has led to some controversies about species circumscription.

The use of rRNA sequences as indicators of evolutionary

${ }^{*}$ Corresponding author. Mailing address: Laboratoire de Génétique et Microbiologie, INRA U.A. 952, Université Henri Poincaré, BP 239, F-54506 Vandoeuvre-lès-Nancy, France. Phone: (33) 83912193. Fax: (33) 83912500 . Electronic mail address: decaris@nancy.inra.fr.

$\dagger$ Present address: Institute of Child Health, Division of Cell and Molecular Biology, University of London, London WC1N 1EH, United Kingdom. divergence is now widespread, and the advantage of this method over classical taxonomic approaches has been well documented (64). 16S rRNA sequence analysis is a powerful and accurate method for determining phylogenetic relationships and is commonly used to determine inter- and intrageneric relationships. Nevertheless, as evolutionary distances decrease, there is a point at which there is insufficient base sequence diversity to differentiate strains of a given species. The inaccuracy of $16 \mathrm{~S}$ rRNA sequence data makes defining the phylogenetic relationships of closely related species difficult (46).

In eubacterial DNA, the rRNA genetic loci include 16S, 23S, and $5 \mathrm{~S}$ rRNA genes, which are separated by internally transcribed spacer (ITS) regions. It is known that DNA sequences in the $16 \mathrm{~S}$ to $23 \mathrm{~S}(16 \mathrm{~S}-23 \mathrm{~S})$ intergenic spacer region exhibit a great deal of sequence and length variation $(1,33)$. The variations in this region have been shown to be useful for differentiating species of prokaryotes (1). Recently, it has been shown that PCR-restriction fragment length polymorphism analysis of the ribosomal intergenic spacer is a good method for differentiating strains of prokaryotes $(33,43)$. In this study, we investigated phylogenetic relationships among Bifidobacterium spp. The results of comparisons of 16S rRNA and ribosomal DNA (rDNA) sequences allowed us to determine the interspecific relationships of 18 species. In addition, to determine the intraspecific relationships, we compared the 16S-23S ITS sequences of 29 strains representing 18 species and performed phylogenetic analyses.

The aims of this study were to determine Bifidobacterium intrageneric relationships and to determine whether Bifidobacterium species are valid taxa. The results of our study of the 
TABLE 1. Bacterial strains and their 16S rRNA and 16S-23S ITS GenBank accession numbers

\begin{tabular}{|c|c|c|c|c|}
\hline \multirow{2}{*}{ Species } & \multirow{2}{*}{ Strain $^{a}$} & \multirow{2}{*}{ Source of isolation } & \multicolumn{2}{|c|}{ GenBank accession no. } \\
\hline & & & 16S rRNA & 16S-23S rDNA \\
\hline $\begin{array}{l}\text { Gardnerella vaginalis } \\
\text { Bifidobacterium spp. }\end{array}$ & ATCC $14018^{\mathrm{T}}$ & Human vagina & M58744 & \\
\hline $\begin{array}{l}\text { Bifidobacterium spp. } \\
\text { B. adolescentis }\end{array}$ & & & & \\
\hline $\begin{array}{l}\text { B. adolescentis } \\
\text { B. adolescentis }\end{array}$ & $\begin{array}{l}\text { ATCC } 11146 \\
\text { ATCC } 15703^{\mathrm{T}}\end{array}$ & $\begin{array}{l}\text { Feces of human adult } \\
\text { Feces of human adult }\end{array}$ & M58729 & U09511 \\
\hline B. adolescentis & CIP $6459^{\mathrm{T}}$ & Feces of human adult & $1050 / 29$ & U09512 \\
\hline B. adolescentis & CIP 6460 & Feces of human adult & & U09513 \\
\hline B. adolescentis & CIP 6461 & Feces of human adult & & U09514 \\
\hline B. angulatum & ATCC $27535^{\mathrm{T}}$ & Feces of human adult & & U09515 \\
\hline B. animalis & ATCC $25527^{\mathrm{T}}$ & Feces of rat & X70971 & U09858 \\
\hline B. animalis & ATCC 27536 & Feces of chicken & & L36967 \\
\hline B. asteroides & ATCC $25910^{\mathrm{T}}$ & Intestine of Apis mellifera & M58730 & U09516 \\
\hline B. bifidum & ATCC 11147 & Unknown & & U09526 \\
\hline B. bifidum & ATCC $29521^{\top}$ & Feces of human infant & M38018 & \\
\hline B. bifidum & CIP $56-7^{\top}$ & Feces of human infant & & U09517 \\
\hline B. bifidum & CIP 6465 & Feces of human infant & & U09831 \\
\hline B. breve & ATCC $15700^{\mathrm{T}}$ & Feces of human infant & M58731 ${ }^{b}$ & \\
\hline B. breve & CIP $6469^{\mathrm{T}}$ & Feces of human infant & X70973 & U09520 \\
\hline B. breve & CIP 6468 & Feces of human infant & & U09519 \\
\hline B. breve & CIP 6470 & Feces of human infant & & U09521 \\
\hline B. breve & ATCC 15698 & Feces of human infant & X70972 & U09518 \\
\hline B. catenulatum & ATCC $27539^{\mathrm{T}}$ & Feces of human adult & M58732 & U09522 \\
\hline B. choerinum & CIP $103378^{\mathrm{T}}$ & Feces of pig & & L36968 \\
\hline B. coryneforme & ATCC $25911^{\mathrm{T}}$ & Intestine of Apis mellifera & $\mathrm{M} 58733^{b}$ & U09523 \\
\hline B. cuniculi & ATCC $27916^{\mathbf{T}}$ & Feces of rabbit & M58734 ${ }^{b}$ & \\
\hline B. cuniculi & CIP $103379^{\mathrm{T}}$ & Feces of rabbit & & U09790 \\
\hline B. dentium & ATCC $27534^{\mathrm{T}}$ & Oral cavity & & U10434 \\
\hline B. dentium & ATCC 15423 & Lung abscess in human & M58735 & \\
\hline B. globosum & ATCC $25865^{\mathrm{T}}$ & Rumen cattle & M58736" & U09524 \\
\hline B. indicum & ATCC $25912^{\mathrm{T}}$ & Intestine of Apis cerana & M58737 & U09791 \\
\hline B. infantis & ATCC $15697^{\mathrm{T}}$ & Feces of human infant & M58738 & U09792 \\
\hline B. infantis & ATCC 25962 & Feces of human infant & & U09525 \\
\hline B. infantis & CIP 6378 & Unknown & & U09527 \\
\hline B. longum & ATCC $15707^{\mathrm{T}}$ & Feces of human adult & M58739 $9^{b}$ & \\
\hline B. longum & ATCC 15708 & Feces of human infant & U10152 & U09832 \\
\hline B. magnum & ATCC $27540^{\mathrm{T}}$ & Feces of rabbit & M58740 & U09878 \\
\hline B. minimum & ATCC $27538^{\mathrm{T}}$ & Sewage & M58741 ${ }^{b}$ & \\
\hline B. pseudolongum & ATCC $25526^{\mathrm{T}}$ & Feces of pig & $\mathrm{M} 58742^{b}$ & U09879 \\
\hline B. suis & ATCC $27533^{\mathrm{T}}$ & Feces of pig & $\mathrm{M}^{2} 8743^{b}$ & \\
\hline B. suis & CIP $103377^{\mathrm{T}}$ & Feces of pig & & \\
\hline B. thermophilum & ATCC $25525^{\mathrm{T}}$ & Feces of pig & U10151 & U09528 \\
\hline
\end{tabular}

a The strains were obtained from the American Type Culture Collection (ATCC) or the Collection de l'Institut Pasteur (CIP). The type strains were designated by Reuter (45). The following pairs of strains are synonymous: B. adolescentis ATCC $15703^{\mathrm{T}}$ and B. adolescentis CIP $6459^{\mathrm{T}} ; B$. bifidum ATCC $29521^{\mathrm{T}}$ and B. bifidum CIP $56-7^{\mathrm{T}}$; B. breve ATCC $15700^{\mathrm{T}}$ and B. breve CIP $6469^{\mathrm{T}}$; B. cuniculi ATCC $27916^{\mathrm{T}}$ and B. cuniculi CIP $103379^{\mathrm{T}}$; and B. suis ATCC $27533^{\mathrm{T}}$ and B. suis CIP $103377^{\mathrm{T}}$.

${ }^{b}$ 16S rRNA sequence obtained by Larsen et al. (21).

ITS polymorphisms allowed us to identify each Bifidobacterium strain accurately.

\section{MATERIALS AND METHODS}

Bacterial strains and culture conditions. Bacterial strains were provided directly by either the American Type Culture Collection or the Collection de l'Institut Pasteur. The strains whose sequences were determined in this study and the reference strains used for comparison when phylogenetic trees were constructed are shown in Table 1 . Table 1 includes the strain designations, the sources of the strains, and the GenBank accession numbers for the 16S rRNA and 16S-23S ITS sequences.

All Bifidobacterium strains were cultivated in the same medium, as described previously (4).

Isolation and purification of RNA. Undegraded RNA was isolated by using a single guanidinium thiocyanate step and phenol-chloroform extraction (7).

PCR amplification and purification of product. Genomic DNAs from all of the strains were prepared as described previously by Marmur (27). The bacterial cells were lysed as described previously by using lysosyme (27); none of the species was lysis resistant when the lysosyme was used at the end of the exponential growth phase. PCR amplification of the ITS was performed by using a Geneamp kit (Perkin-Elmer) (30). The PCR primers used to amplify the spacer region were selected from the sequences of 16S and 23S rRNA genes conserved in various bacteria $(5,20,32-34,36,61,62)$. Primer $\mathrm{L}$ was immediately adjacent to the $16 \mathrm{~S}-23 \mathrm{~S}$ spacer; the sequence of this oligonucleotide was $5^{\prime}$-GCTGGAT CACCTCCTTTCT-3', which corresponded to a conserved sequence at the $3^{\prime}$ end of the 16S rRNA (from position 1525 to position 1543 on the Escherichia coli $16 \mathrm{~S}$ rRNA). The sequence of primer $\mathrm{R}$ was deduced from an alignment of $23 \mathrm{~S}$ rRNA 5 ' sequences (from position 23 to position 40 on the $E$. coli $23 \mathrm{~S}$ rRNA); the sequence of primer $R$ was 5'-CTGGTGCCAAGGCATCCA-3'. These primers were supplied by Eurogentec, Seraing, Belgium. The PCR conditions which we used were as follows: 30 cycles consisting of $94^{\circ} \mathrm{C}$ for $1 \mathrm{~min}, 53^{\circ} \mathrm{C}$ for $1 \mathrm{~min}$ and $72{ }^{\circ} \mathrm{C}$ for $2 \mathrm{~min}$, followed by one 5 -min chain elongation step at $72^{\circ} \mathrm{C}$. All amplification reactions were performed in a PREM temperature controller (LEP Scientific). The total volume of each amplification reaction mixture was $100 \mu \mathrm{l}$, and $100 \mathrm{ng}$ of total DNA was used as the template. The amplification products were purified on cDNA spun columns (Pharmacia) as recommended by the manufacturer.

Sequencing methods. (i) 16S rRNA sequencing. rRNA sequences were determined as described previously $(20,42)$ by using $\alpha{ }^{35}$ S-labeled dATP and a reverse transcriptase RNA sequencing kit (United States Biochemicals). DNA primers complementary to 10 universally conserved regions of $16 \mathrm{~S}$ rRNA were either kindly provided R. Christen or obtained from Eurogentec. The 10 primers complemented positions 98 to 119 (primer S2; TTACTCACCCGTCCGC CACTC), 342 to 356 (primer S4; CTGCTGCCTCCCGTA), 518 to 534 (primer S6; TATTACCGCGGCTGCTG), 684 to 702 (primer S8; CTACGCATTTCAC CGCTAC), 786 to 802 (primer S9; CTACCAGGGTATCTAAT), 906 to 925 (primer S10; CCGTCAATTCATTTGAGTTT), 1099 to 1115 (primer S12; 
AAGGGTTGCGCTCGTTG), 1223 to 1240 (primer S14; CATTGTAG CACGTGTGTA), 1384 to 1400 (primer S15; CGGTGTGTACAAGGCCC), and 1491 to 1509 (primer S17; GGTTACCTTGTTACGACTT) of the 16S rRNA (E. coli nucleotide numbering).

For sequencing we used the RT RNA sequencing kit and the standard procedures recommended by the manufacturer.

(ii) 16S-23S spacer sequencing. For amplified DNA sequencing we used Vent (exo-)DNA polymerase as recommended by the manufacturer and a Circum Vent thermal cycle dideoxy DNA sequencing kit (Biolabs). In each reaction either primer $\mathrm{L}$ or primer $\mathrm{R}$ was annealed to a complementary single-stranded stretch of DNA. Repetitive cycles of denaturation, annealing, and chain extension from small amounts of template molecules resulted in linear amplification of reaction products and a strong sequencing signal. In each cycle, the temperature was increased to $95^{\circ} \mathrm{C}$ to denature the double-stranded DNA, decreased to $55^{\circ} \mathrm{C}$ to anneal the primer to the template, and then increased to $72^{\circ} \mathrm{C}$ for the elongation step involving enzymatic synthesis. A total of 25 cycles were completed. The nucleotide fragments produced in the chain elongation reactions were separated on $55-\mathrm{cm}$ wedge-shaped $5 \%(\mathrm{wt} / \mathrm{vol})$ polyacrilamide- $42 \%$ urea gels by using a Sequi-Gen nucleic acid sequencing cell (Bio-Rad).

Analysis of sequence data. The $16 \mathrm{~S}$ rRNA gene sequences which we determined and the sequences of the other bifidobacteria and reference strains obtained from the GenBank database and the Ribosomal Database Project (21) were aligned by using the MUST package (37). The 16S rRNA sequences were first aligned by using the Clustal V program (17), and then the alignments were corrected by hand and analyzed by the neighbor-joining method of Saitou and Nei (47) by using the neighbor-joining program of MUST.

The stability of relationships was assessed by using the bootstrap method (10). A total of 1,000 bootstrap trees were generated for each data set by using the NJBoot program of MUST. A similar analysis was performed by using the ITS sequences.

Nucleotide sequence accession numbers. The 16S rRNA gene and ITS sequences which we determined have been deposited in the GenBank Data Library under the accession numbers shown in Table 1.

\section{RESULTS}

Construction of a phylogenetic tree based on 16S rRNA sequence comparison results. The $16 \mathrm{~S}$ rRNA sequences of the following Bifidobacterium strains belonging to four species were determined: Bifidobacterium breve ATCC 15698 and CIP $6469^{\mathrm{T}}$ (T = type strain), Bifidobacterium longum ATCC 15708 , Bifidobacterium animalis ATCC $25527^{\mathrm{T}}$, and Bifidobacterium thermophilum ATCC $25525^{\mathrm{T}}$. The $16 \mathrm{~S}$ rDNA sequences of 16 other Bifidobacterium species were described by Larsen et al. for the Ribosomal Database Project (21). The five Bifidobacterium 16S rRNA sequences which we determined were compared with the sequences available in the GenBank database. The levels of $16 \mathrm{~S}$ rRNA sequence similarity are shown in Table 2. The levels of similarity for the 18 Bifidobacterium species examined ranged from 92 to $99 \%$. Despite considerable phenotypic diversity, the members of the genus Bifidobacterium exhibit rather high levels of relatedness, which are reflected by their similar DNA G + C contents (for a review, see reference 3 ).

A phylogenetic tree was constructed by using distance matrix data obtained from the 16S rRNA sequences and the neighbor-joining method (47). This tree was based on 1,437 unambiguously aligned positions, and 181 of these positions were informative under the parsimony criterion. The tree was rooted by using the genus Gardnerella, which was the genus that was most closely related to the genus Bifidobacterium (35). Figure 1 is a dendrogram which shows the phylogeny of the genus Bifidobacterium. All of the bifidobacteria fell into six major clusters of species which were characterized by high bootstrap values $(>84 \%)$. The phylogenetic relationships determined in our analysis were in general consistent with a previous dendrogram based on DNA-DNA homology data (22), but there were some differences, which are discussed below.

Clusters 1 and 4. The species Bifidobacterium minimum and Bifidobacterium bifidum were included in clusters 1 and 4 , respectively. These species can be easily recognized by their murein types, Lys-Ser and Orn (Lys)-D-Ser-D-Asp, respectively (for a review, see reference 3 ). Although B. bifidum is the type species of the genus, it exhibited no significant affinity with any other species. These data are consistent with those of Lauer and Kandler (22), who showed that B. bifidum exhibited only a low level of relatedness (about 25\%) with all of the other species used in this study and that there was no indication of a distinct affinity with any of the other clusters.

Cluster 2. Cluster 2 included B. thermophilum, Bifidobacterium coryneforme, and Bifidobacterium asteroides. The last two species are bacteria that inhabit the intestines of honeybees (52). Since $B$. coryneforme and $B$. asteroides have numerous fermentative characteristics in common (3), produce the same fructose-6-phosphate phosphoketolase electrophoretic pattern (3), and are considered phenotypically synonymous (29), we expected that they would be found to be closely related, and this did occur (Fig. 1). We also expected that Bifidobacterium indicum, which exhibited a level of DNA-DNA similarity with $B$. coryneforme of $60 \%$, would also be included in cluster 2 (2). However, our results showed that $B$. indicum ATCC $25912^{\mathrm{T}}$ is not a member of cluster 2 but belongs in cluster 6 and revealed a convincing relationship between this organism and Bifidobacterium infantis ATCC $15697^{\mathrm{T}}$.

Cluster 3. Cluster 3 was composed of Bifidobacterium catenulatum, Bifidobacterium dentium, and Bifidobacterium adolescentis strains. The close phylogenetic relationship of the last two species was expected since Biavati et al. (3) found previously that these organisms cannot be distinguished phenotypically (they have the same murein type and produce the same fructose-6-phosphate phosphoketolase electrophoretic pattern).

Cluster 5. Included in cluster 5 were Bifidobacterium magnum, Bifidobacterium globosum, Bifidobacterium cuniculi, and $B$. animalis. The last two species are characterized by having the same murein type (Orn [Lys]-Ser [Ala]-Ala ${ }_{2}$ ) (for a review, see reference 3 ). This group is consistent with the group described by Lauer and Kandler (22) but is not consistent with the group described by Biavati et al. (3), suggesting that $B$. magnum could be related to $B$. infantis and $B$. longum.

Cluster 6. Cluster 6 was composed of $B$. breve, $B$. indicum, $B$. infantis, B. longum, Bifidobacterium pseudolongum, and Bifidobacterium suis. The close relationship of $B$. breve, $B$. infantis, and $B$. longum was revealed previously by the results of DNA-DNA hybridization experiments (22). In contrast, the close relationship of $B$. infantis ATCC $15698^{\mathrm{T}}$ and $B$. indicum ATCC $25912^{\mathrm{T}}$ was not expected because these two organisms did not exhibit high levels of DNA-DNA hybridization and did not have the same phenotypic characteristics (22). Identical restriction patterns for the genes coding for rRNA (rDNA) were observed only when a Southern blot analysis was performed (data not shown). On the basis of the results of previous studies (for a review, see reference 55) we expected that $B$. pseudolongum would be in cluster 5 (since it is similar to $B$. globosum) rather than cluster 6.

The significance of the branching order of the trees was estimated by performing a bootstrap analysis. First, the bootstrap analysis results provided rather strong support for the monophyly of the clusters (bootstrap values, 86, 86, 97, and 99). They also showed that it would be impossible to determine the relationships of the six clusters (bootstrap values, 21, 24, 48 , and 67 ) by using the complete 16 S rRNA sequences and to determine the relationships of closely related species. Indeed, the variations in the $16 \mathrm{~S}$ rRNA sequences of closely related strains are not sufficient to allow clear determinations of evolutionary distances. The evolutionary rate of the $16 \mathrm{~S}$ rRNA molecule is too low to provide useful information concerning 


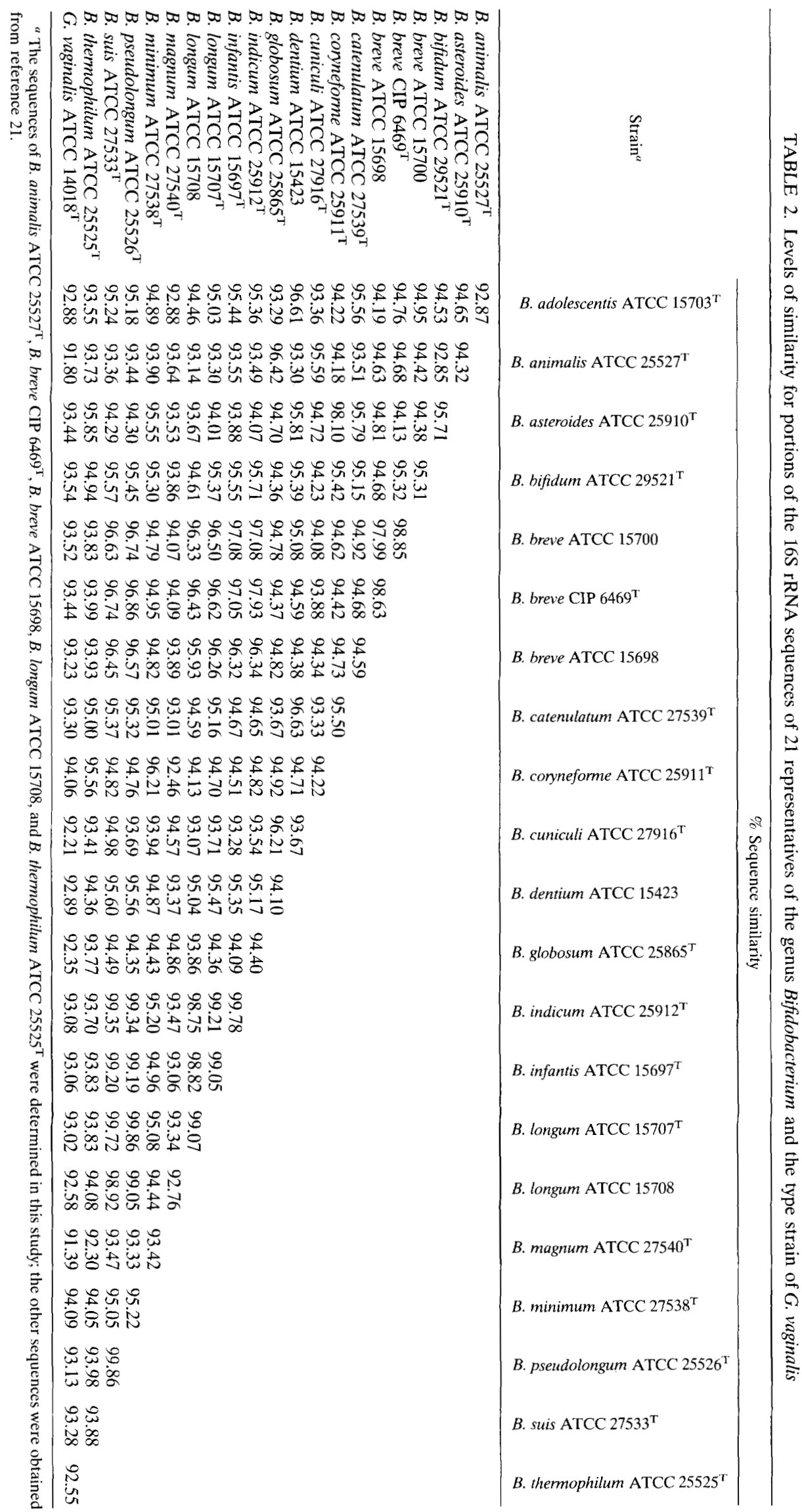




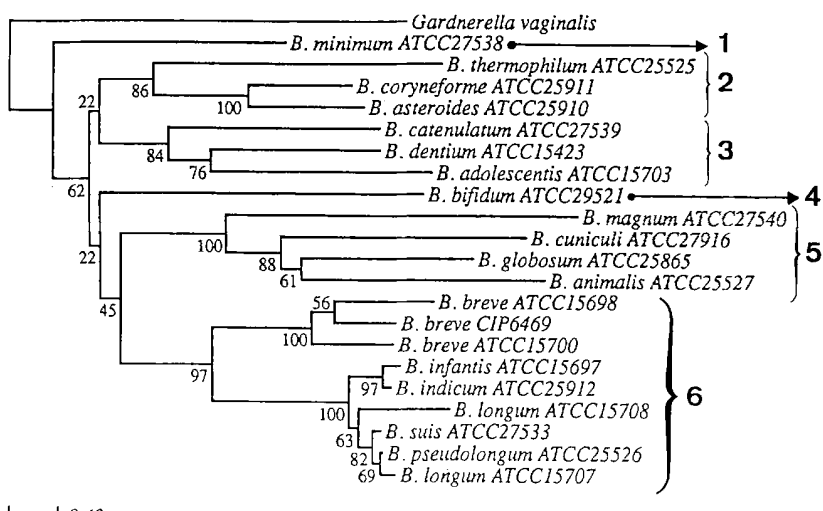

10.43

FIG. 1. Dendrogram based on $16 \mathrm{~S}$ rRNA sequences, showing the relationships of members of the genus Bifidobacterium. The tree was rooted with $G$. vaginalis and was constructed by using the neighbor-joining method and bootstrap values calculated from 1,000 trees. Each number on a branch indicates the number of times (out of 100 ) that the node was supported by the bootstrap analysis results. Bar $=0.43 \%$ sequence divergence. The six major clusters (clusters 1 through 6) are indicated.

strains belonging to the same species. Thus, the evolutionary distances between strains belonging to $B$. breve or $B$. longum could not be determined from the results of $16 \mathrm{~S}$ rRNA sequence comparisons.

$16 \mathrm{~S}$ rRNA sequence analysis is not an appropriate method for delineating species and measuring intraspecies relationships (60). To assess intraspecific phylogenetic relationships, we decided to study a more variable sequence, the $16 \mathrm{~S}-23 \mathrm{~S}$ ITS sequence.

Construction of a phylogenetic tree based on the 16S-23S ITS sequence comparisons (i) Length polymorphism of the PCR-amplified ITS sequences. A total of $3016 \mathrm{~S}-23 \mathrm{~S}$ rDNA spacer regions, obtained from 18 Bifidobacterium species, were amplified by PCR. Using data from previous studies, we determined the minimal number of $m$ loci in Bifidobacterium strains; this number varied between 2 and 5 for the species which we studied $(4,24)$. Although it is known that Bifidobacterium species have more than one $r r n$ locus, in each case only one PCR product was obtained, suggesting that the different ITS copies in each chromosome did not differ in size.

However, the sizes of the PCR products of the strains varied from 263 to 552 bp (Table 3 ). In most cases only small variations in ITS sizes (less than $2 \%$ ) were observed with strains belonging to the same species. The one exception was the $B$. infantis strains, whose ITS sizes differed dramatically; the ITS sizes for the three $B$. infantis strains studied were 263 bp ( $B$. infantis ATCC 25962), 443 bp (B. infantis CIP 6378), and 477 bp (B. infantis ATCC $\left.15697^{\mathrm{T}}\right)$. In addition, the ITS sizes of $B$. adolescentis ATCC 11146 and B. bifidum ATCC 11147 were one-half those observed in other strains of these two species (Table 3). The variations in ITS length observed could have been due in part to variations in the number and type of tRNA sequences found in the spacers $(5,23)$.

Secondary-structure models were constructed for the ITS rDNA sequences of $B$. breve CIP $6469^{\mathrm{T}}, B$. magnum ATCC $27540^{\mathrm{T}}$, and $B$. pseudolongum ATCC $25526^{\mathrm{T}}$ by using the Program Manual for the Wisconsin Package Computer Group software (13). However, tRNA structures were never found, indicating that no tRNA genes were located between the $16 \mathrm{~S}$ and 23S rRNA genes in Bifidobacterium strains. Consistent with these results, a comparison of the 29 ITS sequences which we studied with 12 tRNA sequences published previously by
TABLE 3. Sizes of 16S-23S ITS sequences of Bifidobacterium strains

\begin{tabular}{|c|c|}
\hline Strain & $\begin{array}{l}\text { Size of } 16 \mathrm{~S}-23 \mathrm{~S} \\
\text { ITS sequence (bp) }\end{array}$ \\
\hline B. adolescentis ATCC 11146 & 274 \\
\hline B. adolescentis CIP $6459^{\mathrm{T}}$.. & .... 487 \\
\hline B. adolescentis CIP $6460 \ldots \ldots \ldots$. & ....... 496 \\
\hline B. adolescentis CIP $6461 \ldots . . . .$. & ..... 487 \\
\hline B. angulatum ATCC $27535^{\mathrm{T}}$ & ....... 472 \\
\hline B. animalis ATCC $25527^{\mathrm{T}} \ldots$ & 509 \\
\hline B. animalis ATCC $27536 \ldots \ldots$. & ..... 506 \\
\hline B. asteroides ATCC 25910. & ..... 452 \\
\hline B. bifidum CIP $56-7^{\mathrm{T}} \ldots \ldots \ldots$ & …..... 499 \\
\hline 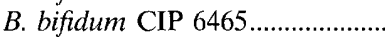 & ......... 491 \\
\hline B. bifidum ATCC $11147 \ldots \ldots \ldots . .$. & ........ 275 \\
\hline B. breve ATCC $15698 \ldots \ldots \ldots \ldots . . . . .$. & ........ 488 \\
\hline B. breve CIP $6468 \ldots \ldots$. & ....... 489 \\
\hline B. breve CIP $6469^{\mathrm{T}}$. & ........... 489 \\
\hline 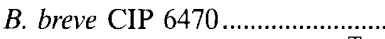 & ........ 496 \\
\hline B. catenulatum ATCC $27539^{\mathrm{T}}$ & .......... 492 \\
\hline B. choerinum CIP $103378^{\mathrm{T}} \ldots \ldots$ & ......... 552 \\
\hline B. coryneforme ATCC $25911^{\mathrm{T}}$. & ....... 459 \\
\hline B. cuniculi CIP $103379^{\mathrm{T}} \ldots \ldots \ldots .$. & ....... 490 \\
\hline B. dentium ATCC $27534^{\mathrm{T}} \ldots .$. & ............ 494 \\
\hline B. globosum ATCC $25865^{\mathrm{T}}$. & ....... 548 \\
\hline B. indicum ATCC $25912^{\mathrm{T}} \ldots$ & ....... 471 \\
\hline B. infantis ATCC $15697^{\mathrm{T}} \ldots \ldots \ldots \ldots$ & .......... 477 \\
\hline 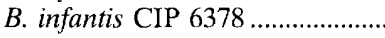 & ....... 443 \\
\hline B. infantis ATCC $25962 \ldots \ldots \ldots \ldots$ & .......... 263 \\
\hline B. longum ATCC $15708 \ldots \ldots \ldots \ldots$ & ......... 476 \\
\hline B. magnum ATCC $27540^{\mathrm{T}} \ldots \ldots$. & …..... 391 \\
\hline B. pseudolongum ATCC $25526^{\mathrm{T}}$ & ........ 541 \\
\hline B. thermophilum ATCC $25525^{\mathrm{T}}$ & ....... 478 \\
\hline
\end{tabular}

Wawrousek et al. (63) revealed no similarity. This finding is consistent with previous data $(34,41,61)$ which clearly showed that no tRNA genes occur in the 16S-23S ITS sequences of Frankia or Streptomyces strains or any other member of the order Actinomycetales.

(ii) ITS sequence comparison. The complete ITS sequences of 29 Bifidobacterium strains were determined by directly sequencing PCR-amplified 16S-23S rDNA spacer products. We found that 2 of the 29 16S-23S ITS sequences examined, (the B. adolescentis ATCC 11146 and B. bifidum ATCC 11147 sequences) were very similar (they differed at less than five positions) but were too heterogeneous to be compared with the sequences of the other Bifidobacterium strains used (levels of divergence, more than $75 \%$ ), even the $B$. adolescentis and $B$. bifidum sequences. Moreover, the restriction patterns and the results of ribotyping and hybridization experiments revealed no relationship between $B$. adolescentis ATCC 11146 and the other $B$. adolescentis strains $(24,26)$. These data are consistent with the results of Scardovi and Trovatelli (51), who concluded that strains ATCC 11146 and ATCC 11147 were erroneously identified as members of the genus Bifidobacterium. A comparison of the B. adolescentis ATCC 11146 and B. bifidum ATCC 11147 16S-23S ITS sequences with the sequences available in the GenBank database revealed striking similarities with 16S-23S ITS sequences of Lactobacillus strains, especially the sequences of Lactobacillus brevis and Lactobacillus heterohiochii (32). This finding is consistent with the results of Kagermeier-Callaway and Lauer (18), who showed by using DNADNA hybridization experiments (levels of similarity, 89 to $98 \%$ ) and $\mathrm{G}+\mathrm{C}$ content analysis that there is a close phylogenetic relationship between members of the genus Lactobacillus and the two strains B. adolescentis ATCC 11146 and B. bifidum ATCC 11147. 
A comparison of the remaining 27 ITS sequences led to the construction of a similarity matrix. The 16S-23S ITS sequence similarity values are shown in Table 4 . We found that each of the strains had a unique ITS sequence, which allowed rapid identification of the organisms. Moreover, the levels of ITS sequence similarity between members of the same species were often greater than the levels of similarity between members of different species; the minimum level of sequence similarity for members of the same species was about $87 \%$. A comparison of $B$. animalis, $B$. bifidum, and $B$. breve strains revealed levels of sequence similarity of more than $93 \%$. In contrast, we estimated that the average level of sequence similarity for $B$. infantis strains was only $39 \%$. B. infantis ATCC 25962 exhibited a level of ITS sequence similarity with $B$. infantis ATCC $15697^{\mathrm{T}}$ or CIP 6378 of only $30 \%$, whereas the level of ITS sequence similarity between strains ATCC $15697^{\mathrm{T}}$ and CIP 6378 was $52 \%$. This result, which indicates that the $B$. infantis strains are not closely related, is consistent with the results of restriction fragment length polymorphism and ribotyping analyses, which revealed no similarity in the patterns of the three strains used in this study $(24,25)$.

Nevertheless, low levels of ITS sequence similarity were commonly obtained when we compared strains belonging to distinct species; these values could be as low as $26 \%$. A low level of ITS similarity was found when we compared $B$. asteroides ATCC $25910^{\mathrm{T}}$ and $B$. infantis ATCC 25962 . Surprisingly, the following four pairs of strains belonging to distinct species exhibited high levels of sequence similarity: $B$. pseudolongum ATCC $25526^{\mathrm{T}}$ and B. globosum ATCC $25865^{\mathrm{T}}$ (level of similarity, $88.9 \%$ ); B. cuniculi CIP $103379^{\mathrm{T}}$ and $B$. dentium ATCC $27534^{\mathrm{T}}$ (level of similarity, 96.3\%); B. infantis ATCC $15697^{\mathrm{T}}$ and $B$. longum ATCC 15708 (level of similarity, 87.3\%); and $B$. infantis ATCC $15697^{\mathrm{T}}$ and B. indicum ATCC $25912^{\mathrm{T}}$ (level of similarity, $97.7 \%$ ). These data raised questions about the previously described taxonomy of these strains.

(iii) Limitation of ITS-based phylogeny because of high evolutionary rates. Figure 2 is an ITS tree which shows Bifidobacterium phylogeny. The significance of the branching order of our trees was estimated by performing a bootstrap analysis. First, it should be noted that the high levels of $16 \mathrm{~S}$ $23 \mathrm{~S}$ ITS sequence variation did not allow us to determine the relationships among distantly related organisms. The lack of ITS sequence similarity and the high frequency of insertiondeletion events could prevent accurate sequence alignment and therefore make phylogenetic relationships difficult to assess. Moreover, because of the high evolutionary rate of the ITS, multiple substitutions often occur at the same nucleotide position. This implies that there has been mutational saturation of ITS sequences, which is known to confuse phylogenetic inferences (for example, see reference 38 ).

However, importantly, we did determine whether ITS sequences could be a reliable tool for inferring phylogenetic relationships between closely related organisms. This was accomplished by comparing the ITS tree with the tree obtained in the 16S rRNA sequence analysis.

(iv) ITS tree and comparison with the $16 \mathrm{~S}$ tree. Overall, the phylogenetic relationships observed in our two trees were similar, which confirmed the hypothesis that ITS sequences could be used in phylogenetic analyses. The ITS tree clearly contained 10 strongly supported groups. The majority of the strains fell into five major groups, which were designated clusters 2 to 6 because of the numbers used on the 16S rRNA sequence tree, and 5 of the 10 groups consisted of single strains (B. infantis ATCC 25962, B. magnum ATCC $27540^{\mathrm{T}}$, B. catenulatum ATCC $27539^{\mathrm{T}}, B$. infantis CIP 6378 , and B. angulatum ATCC $27535^{\mathrm{T}}$ ) (Fig. 2). However, the two trees did differ in some respects. The phylogenetic dendrogram based on the ITS sequences (Fig. 2) differed the dendrogram based on the $16 \mathrm{~S}$ RNA sequences (Fig. 1) by the positions of three species. These differences are discussed below.

Cluster 2. The three species belonging to cluster 2 exhibited high levels of ITS sequence similarity. $B$. coryneforme and $B$. asteroides were more closely related to each other (level of similarity, $83 \%$ ) than to $B$. thermophilum (level of similarity, $61 \%$ ). This result is consistent with the results of DNA-DNA hybridization experiments, which showed that the level of DNA-DNA similarity between $B$. coryneforme and $B$. asteroides was $35 \%$ (22). In contrast, B. thermophilum exhibited lower levels of DNA-DNA similarity with $B$. coryneforme and $B$. asteroides. Nevertheless, cluster 2 is equivalent to the $16 \mathrm{~S}$ rRNA group shown in Fig. 1.

Cluster 3. Cluster 3 was divided into two subgroups, subclusters $3 \mathrm{~A}$ and $3 \mathrm{~B}$. Whereas subcluster $3 \mathrm{~B}$ contained only $B$. catenulatum ATCC $27539^{\mathrm{T}}$, subcluster $3 \mathrm{~A}$ contained $B$. adolescentis, $B$. dentium, and $B$. cuniculi strains. Consistent with the results of the $16 \mathrm{~S}$ rRNA investigations, we found that $B$. adolescentis and $B$. dentium were closely related (average level of similarity, approximately $77 \%$; bootstrap value, 100 ). Three of the four B. adolescentis strains were closely related, whereas ATCC 11146 was clearly misclassified as a Bifidobacterium strain (see above). Although three of the B. adolescentis strains examined exhibited relatively high levels of sequence divergence (maximum level of divergence within the species, $13 \%$ ), the bootstrap value $(100)$ supported the hypothesis that $B$. adolescentis is a phylogenetically significant group. A $B$. adolescentis intraspecific relationship was supported by a high bootstrap value (100), which showed that the ITS sequence comparison technique is a good tool for determining intraspecific phylogenetic relationships.

The presence of B. cuniculi CIP $103379^{\mathrm{T}}$ in subcluster $3 \mathrm{~A}$ was completely unexpected. Even more remarkable was the highly significant association of this strain (level of similarity, $96.3 \%$ ) with $B$. dentium ATCC $27534^{\mathrm{T}}$. In our previous $16 \mathrm{~S}$ rRNA sequence analysis we included $B$. cuniculi ATCC $27916^{\mathrm{T}}$ in cluster 5 . Thus, because the $B$. cuniculi strains used in the two analyses were obtained from two different collections, we wondered whether the currently available strains $B$. dentium ATCC $27534^{\mathrm{T}}$ and B. cuniculi CIP $103379^{\mathrm{T}}$ are the same organism. Our suspicion that $B$. cuniculi CIP $103379^{\mathrm{T}}$ is not a member of $B$. cuniculi was confirmed by the results of a restriction fragment length polymorphism analysis. Indeed, restriction fragment length polymorphism experiments performed with $B$. dentium ATCC $27534^{\mathrm{T}}$ and B. cuniculi CIP $103379^{\mathrm{T}}$ revealed that these organisms differed by only one high-molecular-weight fragment in a $P v u$ II digest (unpublished data). This finding demonstrated that the two strains are related. Thus, it seems that $B$. cuniculi CIP $103379^{\mathrm{T}}$ was misclassified as a member of the species $B$. cuniculi and instead is a $B$. dentium strain. 16S rRNA nucleotide sequence data will be required to shed further light on the taxonomy of these strains.

Another surprising result was the absence of $B$. catenulatum in subcluster $3 \mathrm{~A}$, as found in the $16 \mathrm{~S}$ rRNA analysis. One way to explain the differences between the two trees is to involve multiple changes that accumulated in the ITS sequence, simulated false identities, and masked the actual number of evolutionary events. According to Philippe et al. $(38,39)$, multiple changes can be checked by comparing inferred substitutions with observed differences in the ITS sequences. Such a comparison clearly indicated that none of the ITS sequences except that of $B$. catenulatum (data not shown), was mutationally saturated, indicating that the position of $B$. catenulatum on the ITS sequence tree should not be taken into consideration. 


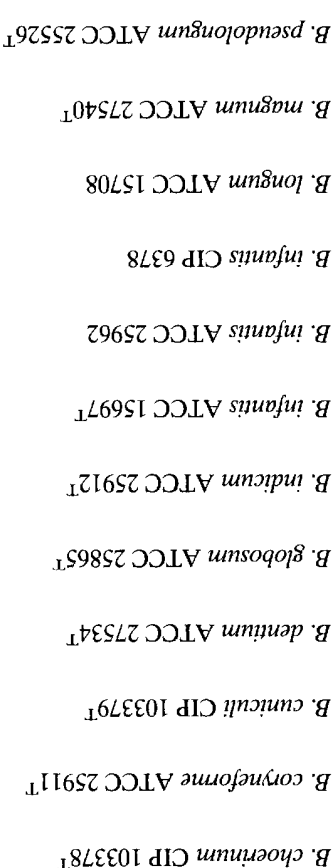

䨠 


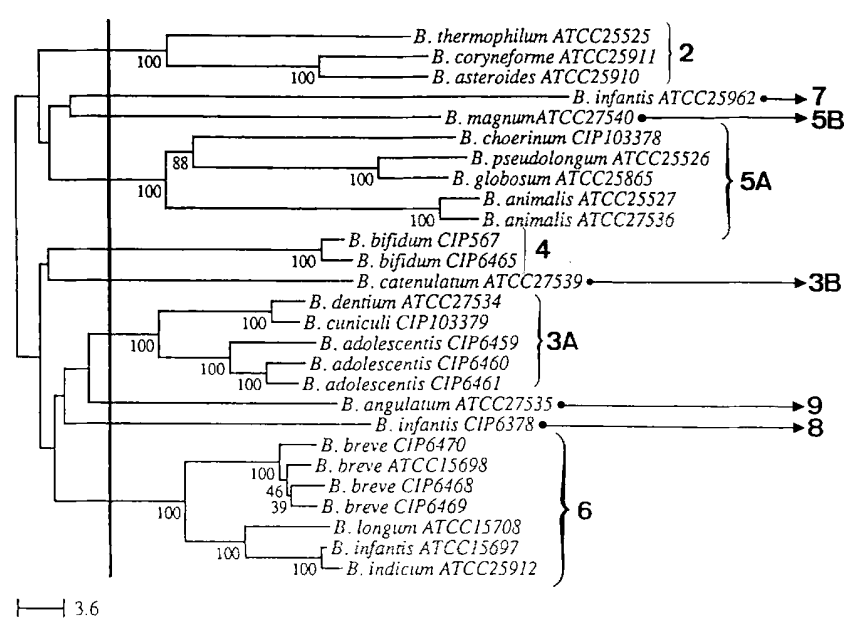

FIG. 2. Dendrogram based on $16 \mathrm{~S}-23 \mathrm{~S}$ ITS sequences, showing the interand intraspecific relationships of members of the genus Bifidobacterium. The tree was constructed by using the neighbor-joining method and bootstrap values calculated from 1,000 trees. Each number on a branch indicates the number of times (out of 100) that the node was supported by the bootstrap analysis results. The nodes to the left of the vertical line were not solved by the ITS phylogeny analysis, whereas the nodes to the right side were solved accurately. The root was placed arbitrarily. Bar $=3.6 \%$ sequence divergence. The designations on the right are cluster and subcluster designations.

Cluster 4. Cluster 4 was phenotypically coherent. This cluster contained all of the $B$. bifidum strains except $B$. bifidum ATCC 11147, which is clearly misclassified as a Bifidobacterium strain (see above). As observed in the 16S rRNA analysis, bootstrap data indicated that $B$. bifidum exhibited no significant affinity with any other organism and clearly belonged to a distinct group. The same observation has been reported previously (22).

Cluster 5. Cluster 5 was divided into two subgroups, subclusters $5 \mathrm{~A}$ and $5 \mathrm{~B}$. Consistent with the results of the $16 \mathrm{~S}$ rRNA analysis and the results of Lauer and Kandler (22), $B$. animalis and $B$. globosum were found to be related and were included in subcluster $5 \mathrm{~A}$. The presence of both $B$. pseudolongum and B. globosum in subcluster $5 \mathrm{~A}$ was expected since workers have reported previously that these two species are related, as determined by DNA-DNA hybridization data (levels of similarity, 69 to $73 \%$ ) (2), phenotypic characteristics (22, 29), and serologic characteristics (58). Therefore, the high level of ITS sequence similarity $(>88 \%$ ) between $B$. pseudolongum and $B$. globosum provided additional evidence that these two taxa should be combined. Thus, our ITS sequence data are consistent with the data of Yaeshima et al. (65), who proposed that these two species should be designated subspecies of the same species. However, these data are not consistent with the data obtained in the $16 \mathrm{~S}$ rRNA sequence analysis, which showed convincingly that $B$. pseudolongum ATCC $25526^{\mathrm{T}}$ and $B$. longum ATCC $15707^{\mathrm{T}}$ are related to each other but not to $B$. globosum ATCC $25865^{\mathrm{T}}$. Taking into account the high level of 16S rRNA sequence similarity between $B$. pseudolongum ATCC $25526^{\mathrm{T}}$ and $B$. longum ATCC $15707^{\mathrm{T}}$ (the sequences of these organisms differed at only six positions), it seems likely that the strain used by Larsen et al. (21) in their $16 \mathrm{~S}$ sequence analysis was misclassified as B. pseudolongum ATCC $25526^{\mathrm{T}}$ and probably is a $B$. longum strain.

Subcluster 5B contained only B. magnum ATCC $27540^{\mathrm{T}}$. Our ITS sequence analysis failed to reveal which strain is the strain that is most closely related to ATCC $27540^{\mathrm{T}}$ (Fig. 2).

Cluster 6. As shown above, cluster 6 included $B$. breve, $B$. longum, B. infantis ATCC $15697^{\mathrm{T}}$, and B. indicum ATCC $25912^{\mathrm{T}}$. We were not able to confirm that these species are closely related to $B$. suis because no PCR product was generated when $B$. suis CIP $103377^{\mathrm{T}}$ was used.

Both the 16S rRNA analysis and the 16S-23S ITS sequence analysis revealed that $B$. infantis ATCC $15697^{\mathrm{T}}$ and $B$. indicum ATCC $25912^{\mathrm{T}}$ are ciosely related (level of $16 \mathrm{~S}$ rRNA sequence similarity, 99.8\%; level of ITS sequence similarity, 97.7\%), suggesting that these organisms belong to the same species. The level of evolutionary divergence between $B$. indicum ATCC $25912^{\mathrm{T}}$ and B. infantis ATCC $15697^{\mathrm{T}}$ seems to be more consistent with classification of these strains as members of a single species than with classification as members of separate species in the same genus. These data contrast with results obtained previously in DNA-DNA hybridization experiments (level of DNA-DNA similarity between $B$. indicum ATCC $25912^{\mathrm{T}}$ and B. coryneforme ATCC $25911^{\mathrm{T}}, 100 \%$ ) (52), with the fermentative characteristics of the organisms, and with the murein type (22), which suggested that $B$. indicum is related to $B$. coryneforme. Our data suggest that the $B$. indicum strain used in our two analyses is a $B$. infantis strain and differs from B. indicum ATCC $25912^{\mathrm{T}}$ as described by Scardovi and Trovatelli (52).

\section{DISCUSSION}

16S rRNA analysis. Comparisons of $16 \mathrm{~S}$ rRNAs have proven to be extremely useful for determining phylogenetic relationships among organisms from the level of domains to the level of moderately closely related species (60). The results which we obtained in this study led to the conclusion that the evolutionary distances exhibited by most bifidobacteria are such that these organisms belong to the same genus. Despite considerable phenotypic diversity, all of the bifidobacteria whose sequences have been determined are closely related (levels of 16S rRNA similarity, >93\%). However, the relationships among the different lineages within the genus Bifidobacterium are largely uncertain (Fig. 1). Judging from the short branch lengths between some nodes, the six clusters appear to have diverged over a relatively short period.

It has been assumed that Gardnerella and Bifidobacterium strains belong to the same genus (9) for the following reasons. The length of the branch from the root of the GardnerellaBifidobacterium cluster to where the branch joins the other actinomycetes was similar to the lengths of the branches that separate the most distantly related mycelium- and spore-forming actinomycete taxa. The genera Gardnerella and Bifidobacterium exhibit close phylogenetic proximity (21). The levels of $16 \mathrm{~S}$ rRNA similarity between Gardnerella vaginalis and representatives of the genus Bifidobacterium (Table 2) are consistent with placing $G$. vaginalis and Bifidobacterium strains in a single genus. However, the opposite result was obtained previously by Greenwood and Picket (15) and Piot et al. (40), who concluded on the basis of DNA-DNA hybridization data that $G$. vaginalis is not a member of the genus Bifidobacterium. Another difference is the $\mathrm{G}+\mathrm{C}$ content of $G$. vaginalis ( 42 to 44 $\operatorname{mol} \%$ ) (16), which is significantly lower than the $\mathrm{G}+\mathrm{C}$ contents of Bifidobacterium spp. (55 to $67 \mathrm{~mol} \%$ ) (3). According to Goodfellow and O'Donnel (14), "if the chromosomal base composition of species in a genus differs by more than $10-12 \%$ $\mathrm{G}+\mathrm{C}$, they must be so distantly related that classification into separate genera is warranted." This is another piece of evidence which supports the view that the genera Gardnerella and Bifidobacterium should be considered two separate taxa.

ITS analysis is complementary to $16 \mathrm{~S}$ rRNA analysis. The evolutionary rate of the $16 \mathrm{~S}-23 \mathrm{~S}$ rDNA spacer region is 10 times greater than the evolutionary rate of the $16 \mathrm{~S}$ rDNA. 
Hence, these two molecules provide different complementary phylogenetic information. While the $16 \mathrm{~S}$ rDNA sequence is a good tool for inferring inter- and intrageneric relationships (11), 16S-23S rDNA spacer sequence comparisons provide information concerning intraspecific links (this study) and allow workers to detect recently diverged species.

ITS tree topology allowed species validity to be confirmed. Our data provide the first demonstration that 16S-23S ITS sequences allow workers to determine relationships among closely related species. In most cases, the ITS tree topology (Fig. 2) showed that the strains belonging to a species are more closely related to the strains of that species than to members of another species. This was true for all strains belonging to $B$. animalis, B. bifidum (except ATCC 11147), and B. breve, and thus the identities of these strains were confirmed.

In contrast, the $B$. infantis strains fell into three different areas on the phylogenetic tree. Because of the lack of phylogenetic coherence in this species, these strains should be placed in separate species. Only the characteristics of $B$. infantis ATCC $15697^{\mathrm{T}}$ are exactly consistent with previously determined $B$. infantis characteristics (which are similar to B. longum characteristics). Additional cooperative work, however, needs to be performed to determine the taxonomic status of the other two B. infantis strains (CIP 6378 and ATCC 25962).

ITS sequence data versus bacterial species. Levels of ITS sequence divergence between strains belonging to the same species may help clarify species definitions that have up to now been controversial. However, it is not possible to determine precise boundary limits on the basis of levels of ITS rDNA sequence relatedness to delineate species. As an approximation, most species groups exhibit levels of $16 \mathrm{~S}-23 \mathrm{~S}$ sequence divergence of $<13 \%$. In this study the maximum level of intraspecific ITS sequence divergence was observed with $B$. adolescentis $(12.7 \%)$, and for most species the levels of intraspecific divergence were much lower $(<6 \%)$. We have reported previously that the $16 \mathrm{~S}$ rRNA sequences of any two species differ by at least $1.5 \%$; hence, it could be argued that two strains belong to the same species if their ITS sequences do not differ by more than $13 \%$. Nevertheless, the exact $16 \mathrm{~S}-23 \mathrm{~S}$ rDNA similarity limits for defining a taxon will have to be determined for each bacterial family.

Most of the strains belonging to distinct species exhibit levels of ITS sequence divergence of more than $13 \%$. Only the following four pairs of strains did not: $B$. pseudolongum ATCC $25526^{\mathrm{T}}$ and $B$. globosum ATCC $25865^{\mathrm{T}} ; B$. cuniculi CIP $103379^{\mathrm{T}}$ and $B$. dentium ATCC $27534^{\mathrm{T}} ; B$. infantis ATCC $15697^{\mathrm{T}}$ and $B$. longum ATCC 15708; and B. infantis ATCC $15697^{\mathrm{T}}$ and $B$. indicum ATCC $25912^{\mathrm{T}}$. An examination of these pair of strains indicated that these taxa should not be viewed as distinct species but should be considered single species (see below). Despite the very good agreement between the two sets of data the 16S rRNA and ITS sequence data), there were significant differences between the two tree topologies. These differences revealed culture collection classification errors. For instance, we found that B. cuniculi CIP $103379^{\mathrm{T}}$ should be reclassified as a $B$. dentium strain.

The most controversial problem concerns the species $B$. infantis and $B$. longum, which are difficult to distinguish by traditional methods. Phylogenetic data obtained from both the $16 \mathrm{~S}$ rRNA sequence analysis (level of divergence, $<0.8 \%$ ) and the 16S-23S ITS sequence analysis (level of divergence, 12.7\%) clearly demonstrated that $B$. longum ATCC $15707^{\mathrm{T}}$ and $B$. infantis ATCC $15697^{\mathrm{T}}$ are closely related. When the guideline value of $13 \%$ is used in conjunction with tree topology information (including confidence values), it seems likely that $B$. longum ATCC 15708 and B. infantis ATCC $15697^{\mathrm{T}}$ should be considered subspecies of a single species. Our doubt concerning the advisability of recognizing $B$. infantis and $B$. longum as separate species is also supported by DNA-DNA hybridization data which showed that the levels of DNA similarity between the two species range from 65 to $80 \%$ (48).

With the exception of $B$. breve, the same taxonomic question could be asked concerning each of the species belonging to cluster 6 . The position of $B$. suis is questionable. Lauer and Kandler (22) previously supported the idea that $B$. infantis, $B$. longum, and $B$. suis should be considered members of a single species on the basis of 16S rRNA similarity data (level of similarity, 99.2\%), DNA-DNA similarity data, fermentative characteristics, and murein types (for a review, see reference 22). On the basis of DNA-DNA similarity and 16S rRNA sequence analysis data, we agree with Lauer and Kandler (22), who combined $B$. longum, $B$. suis, and $B$. infantis in a single species, B. longum.

In conclusion, ITS sequence analysis is a useful technique for identifying bifidobacteria. There is a good correlation between strain relationships determined by ITS sequence studies and corresponding data derived from DNA-DNA hybridization studies.

Previous studies have demonstrated that it is feasible to distinguish bifidobacterial species by using either probes directed at $16 \mathrm{~S}$ rRNA $(12,66)$ or random cloning probes $(26)$. As we have shown previously, rDNA polymorphisms are useful characterizating bifidobacteria found in the human colonic flora (25). Despite ribotyping experiments which allowed us to characterize all strains, it has not been possible to assign each strain to a particular species. In this study, we found that the data obtained by sequencing the $16 \mathrm{~S}-23 \mathrm{~S}$ ITS region are useful for rapid identification or intraspecific phylogenetic studies of strains. Further experiments to identify strain-specific oligonucleotides are in progress.

\section{ACKNOWLEDGMENT}

This study was supported by grants from the Institut National de la Recherche Agronomique, the Ministère de la Recherche et de la Technologie, and the Universite de Nancy 1. We thank the Fondation Dufrenoy of the Ministère de l'Agriculture for financial support of N.L.-B.

We are grateful to $\mathrm{R}$. Christen for kindly providing primers and to Christine Hoyle for her help in the preparation of the manuscript.

\section{REFERENCES}

1. Barry, T., G. Colleran, M. Glennon, L. Dunican, and F. Gannon. 1991. The $16 \mathrm{~S} / 23 \mathrm{~S}$ ribosomal spacer as a target for DNA probes to identify eubacteria. PCR Methods Appl. 1:51-56.

2. Biavati, B., V. Scardovi, and W. E. Moore. 1982. Electrophoretic patterns of proteins in the genus Bifidobacterium and proposal of four new species. Int. J. Syst. Bacteriol. 32:358-373.

3. Biavati, B., B. Sgorbati, and V. Scardovi. 1991. The genus Bifidobacterium, p. 817-833. In A. Balows, H. G. Trüper, M. Dworkin, W. Harder, and K. H. Schleifer (ed.), The prokaryotes, 2nd ed. Springer Verlag, New York.

4. Bourget, N., J.-M. Simonet, and B. Decaris. 1993. Analysis of the genome of the five Bifidobacterium breve strains: plasmid content, pulsed-field gel electrophoresis genome size estimation and $m n$ loci number. FEMS Microbiol. Lett. 110:11-20.

5. Brosius, J., T. J. Dull, D. D. Sleeter, and H. F. Noller. 1981. Gene organization and primary structure of a ribosomal RNA operon from Escherichia coli. J. Mol. Biol. 148:107-127.

6. Chevalier, P., D. Roy, and P. Ward. 1990. Detection of Bifidobacterium species by enzymatic methods. J. Appl. Bacteriol. 68:619-624.

7. Chomszynski, P. N., and N. Sacchi. 1987. Single-step methods of RNA isolation by acid guanidinium thiocyanate-phenol-chloroform extraction. Anal. Biochem. 162:157-159.

8. De Vries, W., S. J. Gerbrandy, and A. H. Stouthamer. 1967. Carbohydrate metabolism in Bifidobacterium bifidum. Biochem. Biophys. Acta 136:415-425.

9. Embley, T. M., and E. Stackbrandt. 1994. The molecular phylogeny and systematics of the actinomycetes. Annu. Rev. Microbiol. 48:257-289.

10. Felsenstein, J. 1985. Confidence limits on phylogenies: an approach using the bootstrap. Evolution 39:783-791. 
11. Fox, G. E., J. D. Wisotzkey, and P. Jurtshuk. 1992. How close is close: 16 S rRNA sequence identity may not be sufficient to guarantee species identity. Int. J. Syst. Bacteriol. 42:166-170.

12. Frothingham, R., A. J. Duncan, and K. H. Wilson. 1993. Ribosomal DNA sequences of bifidobacteria: implications for sequence-based identification of the human colonic flora. Microb. Ecol. Health Dis. 6:23-27.

13. Genetics Computer Group. 1994. Program Manual for the Wisconsin Package, version 5, Sept. 1994. Genetics Computer Group, Madison Wis.

14. Goodfellow, M., and A. G. O'Donnell. 1993. Roots of bacterial systematics, p. 3-54. In M. Goodfellow and A. G. O'Donnell (ed.), Handbook of new bacterial systematics. Academic Press, London.

15. Greenwood, J. R., and M. J. Picket. 1980. Transfer of Haemophilus vaginalis Gardner and Dukes to a new genus, Gardnerella: G. vaginalis (Gardner and Dukes) comb. nov. Int. J. Syst. Bacteriol. 30:170-178.

16. Greenwood, J. R., and M. J. Picket. 1986. The genus Gardnerella, p. 1283-1286. In P. H. A. Sneath, N. S. Mair, M. E. Sharpe, and J. G. Holt (ed.), Bergey's manual of systematic bacteriology, vol. 2. Williams and Wilkins, Baltimore.

17. Higgins, D. G., and P. M. Sharp. 1988. Clustal: a package for performing multiple sequence alignment on a computer. Gene 73:237-244.

18. Kagermeier-Callaway, A. S., and E. Lauer. 1995. Lactobacillus sake Katagiri, Kitahara, and Fukami 1934 is the senior synonym for Lactobacillus bavaricus Stetter and Stetter 1980. Int. J. Syst. Bacteriol. 45:398-399.

19. Kempsell, K. E., Y. E. Ji, I. C. E. Estrada-G., M. J. Colston, and R. A. Cox. 1992. The nucleotide sequence of the promoter, 16S rRNA and spacer region of the ribosomal RNA operon of Mycobacterium tuberculosis and comparison with Mycobacterium leprae precursor rRNA. J. Gen. Microbiol. 138:1717-1727.

20. Lane, D. J., B. Pace, G. J. Olsen, D. A. Stahl, M. L. Sogin, and N. R. Pace. 1985. Rapid determination of $16 \mathrm{~S}$ ribosomal RNA sequences for phylogenetic analysis. Proc. Natl. Acad. Sci. USA 82:6955-6959.

21. Larsen, N., G. J. Olsen, B. L. Maidak, M. J. McCaughey, R. Overbeek, T. J. Macke, T. L. Marsh, and C. R. Woese. 1993. The Ribosomal Database Project. Nucleic Acid Res. 21:3021-3023.

22. Lauer, E., and O. Kandler. 1983. DNA-DNA homology, murein types and enzyme patterns in the type strains of the genus Bifidobacterium. Syst. Appl. Microbiol. 4:42-64.

23. Loughney, K., E. Lund, and J. E. Dahlberg. 1982. tRNA genes are found between the 16S and 23S rRNA genes in Bacillus subtilis. Nucleic Acids Res. 10:1607-1624.

24. Mangin, I. 1994. Typage moléculaire-de souches du genre Bifidobacterium: polymorphisme génétique intraspécifique et intragénérique. Ph.D. thesis. Université Henri-Poincaré, Nancy 1, Vandoeuvre-lès-Nancy, France.

25. Mangin, I., N. Bourget, Y. Bouhnik, N. Bisetti, J.-M. Simonet, and B. Decaris. 1994. Identification of Bifidobacterium strains by rRNA gene restriction patterns. Appl. Environ. Microbiol. 60:1451-1458.

26. Mangin, I., N. Bourget, J.-M. Simonet, and B. Decaris. 1995. Selection of species-specific DNA probes which detect strain restriction polymorphism in four Bifidobacterium species. Res. Microbiol. 146:59-71.

27. Marmur, J. 1961. A procedure for isolation of deoxyribonucleic acid from microorganisms. J. Mol. Biol. 3:208-218.

28. Matteuzzi, D., F. Crociani, G. Zani, and L. D. Trovatelli. 1971. Bifidobacterium suis n. sp.: a new species of the genus Bifidobacterium isolated from pig feces. Z. Allg. Mikrobiol. 11:387-395.

29. Mitsuoka, T. 1984. Taxonomy and ecology of bifidobacteria. Bifidobacteria Microflora 3:11-28.

30. Mullis, K. B., and F. A. Faloona. 1987. Specific synthesis of DNA in vitro via a polymerase-catalyzed chain reaction. Methods Enzymol. 155:335-350.

31. Mutai, M., and R. Tanaka. 1987. Ecology of Bifidobacterium in the human intestinal flora. Bifidobacteria Microflora 6:33-41.

32. Nakagawa, T., M. Shimada, H. Mukai, K. Asada, I. Kato, K. Fujino, and T. Sato. 1994. Detection of alcohol-tolerant Hiochi bacteria by PCR. Appl. Environ. Microbiol. 60:637-640.

33. Navarro, E., P. Simonet, P. Normand, and R. Bardin. 1992. Characterization of natural populations of Nitrobacter spp. using PCR/RFLP analysis of the ribosomal intergenic spacer. Arch. Microbiol. 157:107-115.

34. Normand, P., B. Cournoyer, P. Simonet, and S. Nazareth. 1992. Analysis of a ribosomal RNA operon in the actinomycete Frankia. Gene 111:119-124.

35. Olsen, G. J., C. R. Woese, and R. Overbeek. 1994. The winds of (evolutionary) change: breathing new life into microbiology. J. Bacteriol. 176:1-6.

36. Pernodet, J. L., F. Boccard, M. T. Alegre, J. Gagnat, and M. Guérineau. 1989. Organization and nucleotide sequence analysis of a ribosomal RNA gene cluster from Streptomyces ambofaciens. Gene 79:33-46.

37. Philippe, H. 1993. MUST: a computer package of Management Utilities for Sequences and Trees. Nucleic Acids Res. 21:5264-5272.

38. Philippe, H., and A. Adoutte. 1996. What can phylogenetic patterns tell us about the evolutionary process generating biodiversity?, p. 41-59. In M. Hochberg, J. Clobert, and R. Barbault (ed.), Aspects of the genesis and maintenance of biological diversity. Oxford University Press, Oxford.

39. Philippe, H., U. Sorhannus, A. Baroin, R. Perasso, F. Gasse, and A. Adoutte. 1994. Comparison of molecular and paleontological data in diatoms suggests a major gap in the fossil record. J. Evol. Biol. 7:247-265.

40. Piot, P., E. Van Dyck, M. Goodfellow, and S. Falkow. 1980. A taxonomic study of Gardnerella vaginalis (Haemophilus vaginalis) Gardner and Dukes 1955. J. Gen. Microbiol. 119:373-396.

41. Plohl, M., and V. Gamulin. 1991. Sequence of the 5S rRNA gene and organization of ribosomal RNA operons in Streptomyces rimosus. FEMS Microbiol. Lett. 77:139-144.

42. Qu, L. H., B. Michot, and J. P. Bachellerie. 1983. Improved methods for structure probing in large RNAs: a rapid "heterologous" sequencing approach is coupled to the direct mapping of nuclease accessible sites. Application to the 5 ' terminal domain of eukaryotic $28 \mathrm{~S}$ rRNA. Nucleic Acids Res. 11:5903-5919.

43. Regnery, R. L., C. L. Spruill, and B. D. Plikaytis. 1991. Genotypic identification of rickettsiae and estimation of intraspecies sequence divergence for portions of two rickettsial genes. J. Bacteriol. 173:1576-1589.

44. Reuter, G. 1963. Vergleichenden Untersuchung über die Bifidus-Flora im Sauglings und Erwachsenenstuhl. Zentralbl. Bakteriol. Parasitenkd. Infektionskr. Hyg. Abt. 1 Orig. 191:486-507.

45. Reuter, G. 1971. Designation of type strains for Bifidobacterium species. Int. J. Syst. Bacteriol, 21:273-275.

46. Rogall, T., J. Wolters, T. Flohr, and E. Böttger. 1990. Towards a phylogeny and the definition of species at the molecular level within the genus Mycobacterium. Int. J. Syst. Bacteriol. 40:323-330.

47. Saitou, N., and M. Nei. 1987 . The neighbor-joining method: a new method for reconstructing phylogenetic trees. Mol. Biol. Evol. 4:406-425.

48. Scardovi, V., F. Casalicchio, and N. Vincenzi. 1979. Multiple electrophoretic forms of transaldolase and 6-phosphogluconate dehydrogenase and their relationships to the taxonomy and ecology of bifidobacteria. Int. J. Syst. Bacteriol. 29:312-327.

49. Scardovi, V., and F. Crociani. 1974. Bifidobacterium catenulatum, B. dentium, and $B$. angulatum. Three new species and their deoxyribonucleic acid homology relationships. Int. J. Syst. Bacteriol. 24:6-20.

50. Scardovi, V., and B. Sgorbati. 1974. Electrophoretic types of transaldolase, transketolase and other enzymes in bifidobacteria. Antonie van Leeuwenhoek J. Microbiol. Serol. 40:427-440.

51. Scardovi, V., and L. D. Trovatelli. 1965. The fructose-6-phosphate shunt as a peculiar pattern of hexose degradation in the genus Bifidobacterium. Ann. Microbiol. Enzimol. 15:19-29.

52. Scardovi, V., and L. D. Trovatelli. 1969. New species of bifid bacteria from Apis mellifica L. and Apis indica F. A. contribution to the taxonomy and biochemistry of the genus Bifidobacterium. Zentralbl. Bakteriol. Parasitenkd. Infektionskr. Hyg. Abt. 1 Orig. 123:64-88.

53. Scardovi, V., and L. D. Trovatelli. 1974. Bifidobacterium animalis (Mitsuoka) comb. nov. and the "minimum" and "subtile" groups of new bifidobacteria found in sewage. Int. J. Syst. Bacteriol. 24:21-28.

54. Scardovi, V., L. D. Trovatelli, B. Biavati, and G. Zani. 1979. Bifidobacterium cuniculi, Bifidobacterium choerinum, Bifidobacterium boum, and Bifidobacterium pseudocatenulatum: four new species and their deoxyribonucleic acid homology relationships. Int. J. Syst. Bacteriol. 29:291-311.

55. Scardovi, V., L. D. Trovatelli, G. Zani, F. Crociani, and D. Matteuzzi. 1971. Deoxyribonucleic acid homology relationships among species of the genus Bifidobacterium. Int. J. Syst. Bacteriol. 21:276-294.

56. Scardovi, V., and G. Zani. 1974. Bifidobacterium magnum sp. nov.: a large acidophilic Bifidobacterium isolated from rabbit feces. Int. J. Syst. Bacteriol. 24:29-34

57. Scardovi, V., G. Zani, and L. D. Trovatelli. 1970. Deoxyribonucleic acid homology among the species of the genus Bifidobacterium isolated from animals. Arch. Mikrobiol. 72:318-325.

58. Sgorbati, B., and J. London. 1982. Demonstration of phylogenetic relatedness among members of the genus Bifidobacterium by means of the enzyme transaldolase as an evolutionary marker. Int. J. Syst. Bacteriol. 32:37-42.

59. Sgorbati, B., and V. Scardovi. 1979. Immunological relationships among transaldolases in the genus Bifidobacterium. Antonic van Leeuwenhoek J. Microbiol. Serol. 45:129-140.

60. Stackebrandt, E., and B. M. Goebel. 1994. Taxonomic note: a place for DNA-DNA reassociation and $16 \mathrm{~S}$ rRNA sequence analysis in the present species definition in bacteriology. Int. J. Syst. Bacteriol. 44:846-849.

61. Suzuki, Y., Y. Ono, A. Nagata, and T. Yamada. 1988. Molecular cloning and characterization of an rRNA operon in Streptomyces lividans TK21. J. Bac teriol, 170:1631-1636.

62. Suzuki, Y., and T. Yamada. 1988. The nucleotide sequence of 16S rRNA gene from Streptomyces lividans TK 21. Nucleic Acids Res. 16:370.

63. Wawrousek, E. F., N. Narasimhan, and J. N. Hansen. 1984. Two large clusters with thirty seven transfer RNA genes adjacent to ribosomal RNA gene sets in Bacillus subtilis. J. Biol. Chem. 259:3694-3702.

64. Woese, C. R. 1987. Bacterial evolution. Microbiol. Rev. 51:221-271.

65. Yaeshima, T., T. Fujisawa, and T. Mitsuoka. 1992. Bifidobacterium globosum, subjective synonym of Bifidobacterium pseudolongum, and description of Bifidobacterium pseudolongum subsp. pseudolongum comb. nov. and Bifidobacterium pseudolongum subsp. globosum. Syst. Appl. Microbiol. 15: 380-385.

66. Yamamoto, T., M. Morotomi, and R. Tanaka. 1992. Species-specific oligonucleotide probes for five Bifidobacterium species detected in human intestinal microflora. Appl. Environ. Microbiol. 58:4076-4079. 